\title{
Defesa da ecologia, distância do ambientalismo
}

\section{Defense of ecology, distance from environmentalism}

\author{
Gildo Magalhães \\ Professor, História da Ciência/Faculdade de Filosofia, Letras e Ciências Humanas/Universidade de São Paulo. \\ gildomsantos@hotmail.com
}

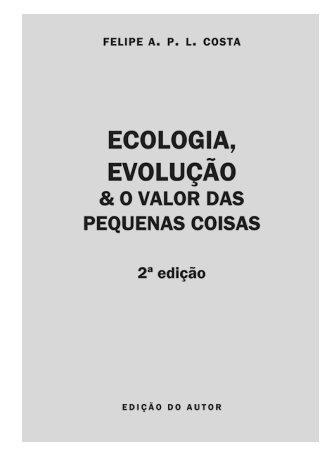

COSTA, Felipe A.P.L. Ecologia, evolução eo valor das pequenas coisas. 2.ed. Viçosa: Edição do autor. 2014. 137p.
A comunicação é uma atividade inerente ao próprio fazer científico, Aque se transformou ao longo dos séculos numa empreitada profissionalizada, envolvendo a publicação em veículos especializados de ideias, métodos e resultados relativos às ciências (Vickery, 2000). No entanto, cada vez mais essa comunicação tende a empregar uma linguagem por demais hermética, servindo primordialmente para uma troca entre os colegas pertencentes a campos específicos do conhecimento, fora do alcance de outros cientistas, para não dizer dos leigos, daqueles que têm, no mais das vezes e quando muito, um conhecimento de nível básico, proporcionado pelo ensino médio. Adicionalmente, verifica-se que muitos cientistas, até mesmo alguns de áreas voltadas para as humanidades, não escrevem bem. Para servir de ponte entre a comunicação científica e o grande público, surgiu o campo que é comumente denominado divulgação científica, também chamado na França de "vulgarização científica" (lá, sem nenhum sentido pejorativo que aqui possa eventualmente ter a palavra "vulgarização").

Na divulgação científica encontramos amiúde escritores com formação em jornalismo e que enfrentam o desafio de transpor a ciência para uma linguagem mais abrangente (Sánchez, 2003; Massarani, Turney, Moreira, 2005). Se esse esforço costuma vir envolto numa roupagem literariamente atraente, por outro lado o jornalismo científico corre o risco, como se verifica tão frequentemente, de perder o rigor das ideias originais, e até mesmo falsear a pretendida tradução do erudito para o popular (Tognolli, 2003). Alguns jornais diários brasileiros, por exemplo, mantêm uma seção de ciência, com resultados nem sempre à altura do propósito da divulgação. Temos ainda o hábito, infelizmente bastante difundido, de pautar o conteúdo dessas notícias na mídia pela publicação de artigos vindos do exterior, como os dos periódicos Nature e Science, em vez de matérias a resultar de trabalhos próprios do jornalismo local (Barata, 2010). Naturalmente, há exceções de bons jornalistas dedicados à divulgação científica que desenvolveram uma tradição respeitável, e há mesmo o caso excepcional de bons cientistas que se tornaram profissionais do jornalismo de divulgação científica - e para citar um nome conhecido, tivemos entre nós nesse perfil a figura pioneira de José Reis. 
Embora também raro, é possível que um cientista, mesmo sem ser jornalista, tenha a preocupação de bem escrever, para que um tema fascinante do ponto de vista científico não se torne árido e possa então atingir um público maior. Um subproduto interessante desse empreendimento da redação clara é quando um texto de divulgação impacta uma pessoa que futuramente se tornará um cientista importante - como aconteceu com James Watson, para quem a leitura de $O$ que é vida?, do físico e pensador Erwin Schrödinger, foi fundamental em sua decisão de estudar a estrutura molecular dos genes.

Não se pode perder de vista tampouco que não é muito nítida a fronteira entre a comunicação, em senso estrito, e a divulgação científica, como pode ser avaliado examinandose uma boa antologia como a de Edmund Bolles (1997). Nela estão recolhidos textos científicos de importância fundamental que são ao mesmo tempo literariamente exemplares, e que perpassam vários séculos, indo desde a Antiguidade de Heródoto e Lucrécio até a contemporaneidade.

As considerações anteriores vêm a propósito de Ecologia, evolução e o valor das pequenas coisas, de Felipe A.P.L. Costa. Este é um biólogo especializado em entomologia e ecologia, conhecido pelas suas colaborações regulares no Observatório da Imprensa, em que emprega o rigor acadêmico para definir de forma certeira conceitos biológicos que a grande imprensa difunde com imprecisão e o público em geral propala incorrendo em erros de significado ou até mesmo de tradução. Naquele veículo eletrônico, o autor também tem divulgado obras e a vida de cientistas menos conhecidos, além de tratar de diversos outros temas, tais como a duvidosa eficácia da política científica brasileira. Uma faceta mais desconhecida e invulgar sua é a campanha pacifista desenvolvida no sítio da internet Poesia contra a guerra, em que reúne contribuições dessa natureza de poetas, principalmente brasileiros, alguns famosos e muitos outros que se inserem na produção poética dita marginal.

Nos textos da obra aqui focalizada, Felipe Costa exercita divulgação científica dirigida primordialmente a um público não especializado. Segue, portanto, na senda ilustre de cientistas como o saudoso zoólogo Stephen Jay Gould, famoso por suas páginas na revista Natural History, depois reunidas em diversos livros de sucesso, vários deles publicados no Brasil.

Nessa segunda edição de Ecologia, evolução e o valor das pequenas coisas, Felipe Costa acrescentou mais seis capítulos aos vinte da edição anterior, divididos em cinco partes. De forma saborosa, discorre sobre evolução biológica, reservas e parques, a relação entre clima e populações, e práticas destrutivas do meio ambiente. São textos curtos, uma boa parte dos quais foi publicada por veículos como Ciência Hoje e Tribuna de Minas. O conteúdo é diversificado, embora focalize sempre aspectos ecológicos e evolutivos. Uma amostra dessa diversidade é a denúncia do relativo descaso dos nossos cientistas com a paisagem nativa da caatinga, ou a pouca atratividade dos insetos (75\% das espécies animais) nas campanhas ambientalistas (e o autor revela como a ingenuidade do movimento ambientalista frequentemente se sobrepõe à ciência), a sugestão de forração com serapilheira nas trilhas de parques naturais, a crítica à falta de atenção dos pesquisadores brasileiros para com a fenologia de árvores tropicais, ou ainda uma queixa quanto à introdução funesta em nosso meio de espécies exóticas (como o mosquito Aedes aegypti e o caracol-gigante-africano). Ao final da obra, há notas e um pequeno glossário. Trata-se de leitura fácil de assuntos que se revelam politicamente intrincados, de 
interesse para o público geral, mas que pode ter também e mais especificamente uma aplicação didática no ensino médio.

Pode-se sugerir que no futuro o autor entenda a evolução biológica de forma não tão rígida, pois ele permanece firmemente ancorado dentro da tradição neodarwinista ortodoxa, sem uma abertura para correntes importantes dentro da biologia, mas discordantes dessa interpretação, como a evolução em quatro dimensões (Jablonka, 2010) ou a realimentação somático-germinativa (Steele, Lindley, Blanden, 1998). O paradigma neodarwinista tem sido recentemente confrontado por alguns cientistas renomados internacionalmente, como a falecida Lynn Margulis, cuja posição se afastou do dogmatismo darwiniano ao se filiar às teorias da simbiogênese, ideias que descendem dos trabalhos do botânico russo Konstantin Mereshkovski. É verdade que nada faz sentido em biologia fora da evolução, mas há teorias e teorias da evolução, e não apenas uma única,vencedora e inamovível, como defendem os adeptos mais ferrenhos da teoria sintética.

Principalmente o grande público é o que mais precisa ser informado de que as controvérsias dentro da ciência são permanentemente uma fonte de inovação e que elas são, aliás, parte do funcionamento normal da atividade científica, para além da ciência paradigmática que se oferece ao grande público nos veículos de divulgação científica. A história das ciências é também a das divergências, algumas das quais mostram uma notável longevidade, pois mesmo depois de declaradas mortas e enterradas ressurgem às vezes de formas inesperadas - aspecto que ainda escapa até a muitos historiadores e filósofos da ciência.

No caso específico da evolução há um agravante, já que qualquer divergência costuma ser erroneamente interpretada como expressão de uma suposta guerra entre religião e ciência - e para sermos justos, essa posição refratária e equivocada não se resume ao jornalismo de divulgação científica, mas integra a própria tradição acadêmica. Apenas quando a divulgação científica conseguir se aprofundar e, à maneira do jornalismo investigativo, se puser a trabalhar com a desconfiança de que cientistas não são tão objetivos e neutros quanto pretendem ser, o resultado será uma apreensão qualitativamente superior do que significa fazer ciência - em que até pequenas coisas podem ter grande valor, como propõe acertadamente o autor.

\section{REFERÊNCIAS}

BARATA, Germana.

Nature e Science: mudança na comunicação da ciência e a contribuição da ciência brasileira (1936-2009). Tese (Doutorado em História Social) - Faculdade de Filosofia, Letras e Ciências Humanas, Universidade de São Paulo. 2010.

BOLLES, Edmund B.

Galileo's commandment: 2,500 years of great scientific writing. New York: W.H. Freeman. 1997.

JABLONKA, Eva.

Evolução em quatro dimensões. São Paulo:

Companhia das Letras. 2010.

MASSARANI, Luísa; TURNEY, Jon; MOREIRA, Ildeu de Castro (Org.).

Terra incógnita: a interface entre ciência e público.
Rio de Janeiro: Vieira e Lendt; UFRJ/Casa da Ciência; Fiocruz. 2005.

SÁNCHEZ Mora, Ana Maria.

A divulgação da ciência como literatura. Rio de Janeiro: EdUFRJ. 2003.

STEELE, Edward J.; LINDLEY, Robyn A.; BLANDEN, Robert V.

Lamarck's signature: how retrogens are changing Darwin's natural selection paradigm. Reading: Perseus. 1998.

TOGNOLLI, Claudio.

A falácia genética. São Paulo: Escrituras. 2003.

VICKERY, Brian C.

Scientific communication in History. London:

Scarecrow. 2000. 